www.nature.com/pj

\title{
Wettability characteristics of poly(ethylene terephthalate) films treated by atmospheric pressure plasma and ultraviolet excimer light
}

\author{
Keiko Gotoh $^{1}$, Akemi Yasukawa ${ }^{1}$ and Yasuyuki Kobayashi ${ }^{2}$
}

Two dry processes, atmospheric pressure plasma (APP) exposure and $172 \mathrm{~nm}$ ultraviolet (UV) excimer light irradiation, were carried out to enhance the hydrophilic nature of poly(ethylene terephthalate) (PET) film. The wettability change in the PET film surface after the processes were carried out was recorded by the wetting force measurements employing the Wilhelmy method. After the dry processes, drastic decreases in the advancing and receding contact angles of water were observed, especially for the APP exposure. The advancing angle on the treated PET surface was found to increase by rinsing with water or aging in air, whereas the receding one remained almost the same. The hydrophobic recovery diminished more rapidly for the UV-treated film. Surface characterizations of the PET film were performed. We discuss the influence of the dry processes on the physicochemical properties of the PET surface.

Polymer Journal (2011) 43, 545-551; doi:10.1038/pj.2011.20; published online 16 March 2011

Keywords: contact angle; dry process; hydrophobic recovery; Wilhelmy method; wetting force

\section{INTRODUCTION}

Poly(ethylene terephthalate) (PET) is one of the most common polymers used in the industry because of its high degree of hardness, strength, thermal stability, chemical resistance and formability. ${ }^{1,2}$ However, the hydrophobic nature of PET can be a disadvantage for applications such as adhesion, painting, printing, metallization and so on. Therefore, chemical ${ }^{3}$ and physical modifications have been carried out to make the PET surface more hydrophilic. Typical physical modification techniques are plasma exposure and UV light radiation, and much basic and applied research on these dry processing techniques has been conducted in recent decades. ${ }^{4-12}$

There are two theoretically different techniques for the generation of plasma under an atmospheric pressure: the direct plasma technique using dielectric barrier discharge and the remote plasma technique using after glow. ${ }^{13}$ Compared with the direct plasma technique, the remote plasma technique cannot easily create a homogeneous plasma over a wide area. However, remote APP jet devices generate plasma plumes in open space rather than in confined discharge gaps, and there are no limitations on the sizes of the objects to be treated. ${ }^{14-16}$ In addition, the plasma jet source can be efficiently processed with an output power higher than other atmospheric plasma sources such as dielectric barrier discharge and can produce a number of high-density active species with various gases and gas mixtures. ${ }^{17-19}$ On the other hand, UV radiation, which can cause the photodissociation and ablation of the polymers, ${ }^{20}$ has also been applied to alter the physicochemical properties of polymer surfaces. Although excimer lasers in comparison with excimer lamps have often been used for studies on the UV treatment, the relatively small cross-section of the excimer laser beam and high threshold energy make it difficult to treat large areas of polymer surfaces efficiently. ${ }^{21}$ In this study, the modification of the PET surface was performed using the APP jet device and the UV excimer lamp.

In the application of dry processes to polymer surface modification, there is a serious problem because polymer surfaces after the modification are unstable due to the high mobility and reorientation of macromolecules. ${ }^{22,23}$ Therefore, the water contact angles on the PET surfaces treated by two dry processes are determined as a function of the aging time by the Wilhelmy method. This technique is not only an ideal method for obtaining high-precision contact angles calculated from the wetting force but also enables one to obtain a thermodynamically significant Young contact angle at the threephase contact line by moving the three-phase contact line at a constant velocity. ${ }^{24}$

The stability of the PET surface after the treatments was examined from the viewpoint of the contact angle hysteresis. After attaining the wettability plateau, surface characterization with respect to the surface free energy, surface chemical element and surface topography was carried out, and the effect of the dry processes on the physicochemical properties of the PET surface is discussed.

${ }^{1}$ Faculty of Human Life and Environment, Nara Women's University, Nara, Japan and 2Electronic Materials Research Division, Osaka Municipal Technical Research Institute, Osaka, Japan

Correspondence: Professor Dr K Gotoh, Faculty of Human Life and Environment, Nara Women's University, Kita-uoya-nishi-machi, Nara 630-8506, Japan. E-mail: k-gotoh@cc.nara-wu.ac.jp

Received 11 November 2010; revised 25 January 2011; accepted 26 January 2011; published online 16 March 2011 


\section{EXPERIMENTAL PROCEDURE}

\section{Materials}

As a PET material, biaxially oriented PET film that was $188 \mu \mathrm{m}$ in thickness (EMBLET SA-188, Unitika, Japan) was used for determining the contact angles by the Wilhelmy technique. Before use, the PET film was ultrasonically cleaned in water.

Diiodomethane, ethylene glycol and $n$-heptane were extra pure grade reagents and used without further purification. The water was purified (resistivity of $18 \mathrm{M} \Omega \mathrm{cm}$ ) using a Direct-Q UV apparatus (Millipore, Billerica, MA, USA).

\section{Surface treatment}

The surface treatment of the PET film was carried out using two types of dry processes, APP exposure and UV excimer light irradiation. The PET film of $\sim 0.5 \mathrm{~mm}$ in width was cut, and both sides were treated.

The APP exposure was performed using plasma pretreatment equipment (Plasmatreat $\mathrm{GmbH}$, Steinhagen, Germany) consisting of a plasma generator (FG1001), a high-voltage transformer (HTR1001) and a rotating nozzle jet (RD1004). The APP was generated by means of a high-voltage discharge inside the nozzle jet coupled to the stepped high-frequency pulse current power supply (plasma generator). ${ }^{25}$ The operating voltage, current and frequency were adjusted to be $285 \pm 5 \mathrm{~V}, 6.0 \pm 0.1 \mathrm{~A}$ and $16 \pm 3 \mathrm{kHz}$, respectively. The reactive gas used was the ambient air compressed to $0.3 \mathrm{MPa}$ at room temperature. The plasma nozzle was set vertically, from which a jet of $20 \mathrm{~mm}$ in diameter was emitted. The plasma processing parameters were chosen with references to the experimental results in the previous paper. ${ }^{26}$ The film surface was horizontally displaced from the nozzle at a separation distance, $D$, which was varied between 5 and $20 \mathrm{~mm}$. During the exposure, the film was moved in the horizontal direction at a constant velocity, $V$. The velocity was controlled at 0.16 and $0.81 \mathrm{~m} \mathrm{~s}^{-1}$ and the corresponding exposure time was calculated to be 0.125 and $0.025 \mathrm{~s}$, respectively. The number of treatment cycles, $N$, was 2 .

UV excimer light was irradiated on the PET film using an UV excimer lamp at a wavelength of $172 \mathrm{~nm}$ in ambient air using a $\mathrm{Xe}_{2}$ excimer vacuum UV apparatus (UER20-172, Ushio, Tokyo, Japan). The intensity of the UV excimer light at the upper $\mathrm{SiO}_{2}$ glass window of the lamp house was determined to be $15.8 \mathrm{~mW} \mathrm{~cm}^{-2}$ using an UV monitor system (UIT-150 and VUV-S172, Ushio). The PET film was placed in contact with the window. The UV irradiation time was varied between 2 and $90 \mathrm{~s}$.

After the dry treatments, the PET films were stored in a desiccator maintained at $20 \pm 1{ }^{\circ} \mathrm{C}$ and $30 \pm 1 \% \mathrm{RH}$.

\section{Wetting force measurement}

The advancing and receding contact angles of water on the PET film were determined by the wetting force measurement employing the Wilhelmy method. A PET film strip of $\sim 0.5 \mathrm{~mm}$ in width and $10 \mathrm{~mm}$ in length was suspended from the arm of an electrobalance (Model C-2000, Cahn Instruments, Cerritos, CA, USA). A glass vessel containing water was placed on the platform connected to the stepping motor (MP-20L, MICOS, Eschbach, Germany) just below the film strip. The water surface was raised at an interfacial moving velocity of $0.3 \mathrm{~mm} \mathrm{~min}^{-1}$ (ref. 24) until $\sim 2 \mathrm{~mm}$ of the lower film part was immersed. Then, the water surface was moved down to the original position. A continuous weight recording was obtained during immersion-withdrawal cycles. The advancing and receding contact angles were calculated from the advancing and receding wetting forces, respectively, using the Wilhelmy equation. ${ }^{27}$ The effective perimeter of the film was calculated from the wetting force obtained using $n$-pentane by assuming the contact angle to be zero. ${ }^{27}$ The contact angles were measured for 4-8 samples prepared under the same conditions.

The contact angles of diiodomethane and ethylene glycol were also measured for the estimation of the surface-free energy components of the PET film. The Lifshitz-van der Waals component and the Lewis acid and base parameters were calculated from the van Oss-Chaudhury-Good equation ${ }^{28}$ by substituting the measured contact angles of water, diiodomethane and ethylene glycol and their referential surface-free energy components. ${ }^{29}$

\section{Surface analyses}

The chemical composition and the roughness of the PET film surfaces before and after the dry treatments were characterized by X-ray photoelectron spectroscopy (XPS) and atomic force microscopy, respectively.

XPS analysis was carried out using an Axis-Ultra DLD spectrometer (Kratos, Manchester, UK) using monochromated $\mathrm{Al} \mathrm{K}_{\alpha}$ radiation at $1486.7 \mathrm{eV}(120 \mathrm{~W})$ with charge neutralization. Survey spectra and high-resolution spectra of the core levels of C1s, N1s and O1s were acquired with a pass energy of 80 and $20 \mathrm{eV}$, respectively, and a slot aperture $\left(0.3 \times 0.7 \mathrm{~mm}^{2}\right)$. Spectra were collected at a photoelectron take-off angle of $30^{\circ}$. The pressure in the analytical chamber was maintained $\sim 10^{-8} \mathrm{~Pa}$. The analyzed surface layer was within a few nanometers. All XPS binding energies were referenced to the C1s peak of adventitious carbon at a binding energy of $284.8 \mathrm{eV}$. The collected spectra were deconvoluted with a Gaussian-Lorenzian approximation after Shirley background subtraction using Vision 2 software.

The atomic force microscopy images were collected using a Nanoscope IIIa (Digital Instruments, Tonawanda, NY, USA) in a tapping mode. The surface roughness parameters, average roughness, root mean square roughness and maximum roughness depth were determined from the images obtained in a $1 \times 1 \mu \mathrm{m}$ area.

\section{RESULTS AND DISCUSSION}

\section{Effect of dry processing on the wettability of PET}

Figure 1 shows the typical weight recordings of the PET films untreated and treated by the APP jet and the UV excimer light. The points 'a', 'b', and 'c' show the moments when the water surface
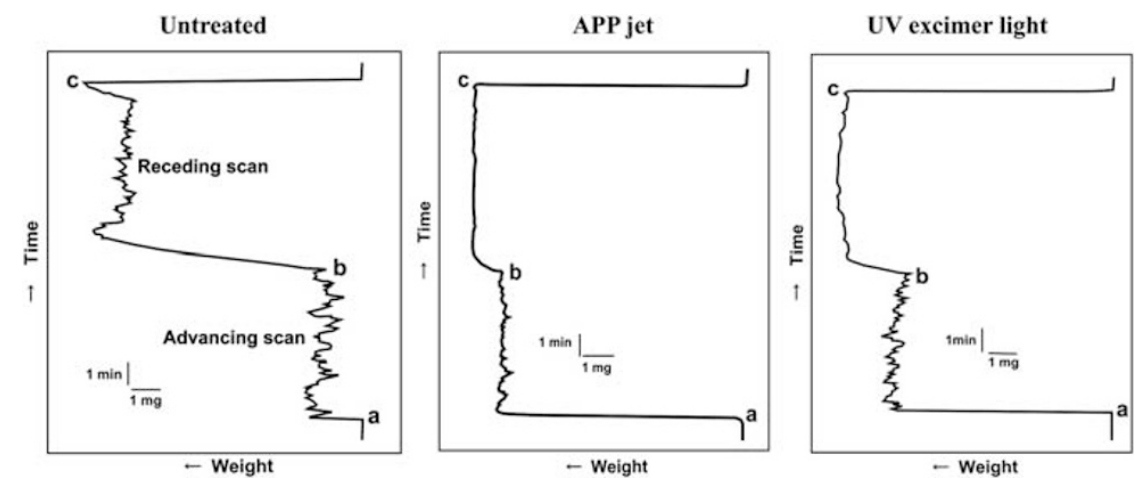

Figure 1 Typical weight recordings of the poly(ethylene terephthalate) (PET) films untreated and treated by atmospheric pressure plasma (APP) jet (the distance between the nozzle and the film: $7 \mathrm{~mm}$, film moving velocity: $0.16 \mathrm{~ms}^{-1}$ ) and ultraviolet (UV) excimer light (irradiation time: $60 \mathrm{~s}$ ). The measurements were carried out within $30 \mathrm{~min}$ after the treatment. The point a corresponds to the moment when the water surface touched the lower edge of the film, the point $b$ to when the direction of the motion of the water surface was reversed and the point $c$ to when the water surface was separated from the lower edge of the film. 
touched the lower edge of the film, when the direction of the motion of the water surface was reversed and when the water surface was separated from the lower edge of the film, respectively. The changes in weight at the points ' $a$ ' and ' $c$ ' correspond to the advancing and receding wetting forces, respectively. Compared with the untreated film, considerable change in the weight recording was observed after both dry processes.

Figure 2 shows the effect of the treatment condition on the advancing and receding contact angles of water on the PET film. In
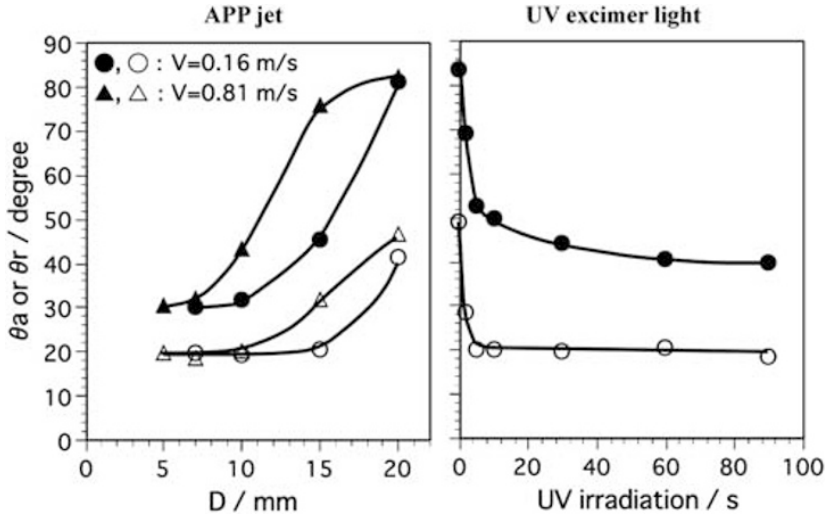

Figure 2 Advancing (closed symbols) and receding (open symbols) contact angles of water, $\theta_{\mathrm{a}}$ and $\theta_{\mathrm{r}}$, respectively, on the poly(ethylene terephthalate) (PET) film treated by atmospheric pressure plasma (APP) jet and ultraviolet (UV) excimer light as a function of the distance between the nozzle and the film, $D$ and UV irradiation time, respectively. the case of the APP-treated PET film, the results are given as a function of $D$. The modification at $V=0.16 \mathrm{~m} \mathrm{~s}^{-1}$ showed lower advancing and receding contact angles than that at $V=0.81 \mathrm{~m} \mathrm{~s}^{-1}$. This tendency is in accordance with the $V$ dependence of the contact angles determined by the conventional sessile drop method in the previous study. ${ }^{26}$ In both cases of $V=0.16$ and $0.81 \mathrm{~m} \mathrm{~s}^{-1}$, the advancing and receding contact angles decreased with decreasing $D$ and became almost constant. Under the conditions of $D=5 \mathrm{~mm}$ and $V=0.16 \mathrm{~m} \mathrm{~s}^{-1}$, the PET film was often deformed because of partial melting at high temperature. In this study, the APP was exposed to the PET film surface under the condition of $D=7 \mathrm{~mm}$ and $V=0.16 \mathrm{~m} \mathrm{~s}^{-1}$. For the UV treatment, the contact angles are plotted against the irradiation time. The advancing and receding contact angles on the UV-treated PET films drastically decreased within a few tens of seconds of UV irradiation and reached saturation. The UV irradiation time was determined to be $60 \mathrm{~s}$ in this study.

Hydrophobic recovery of the PET surface after the dry processing It has been reported that low-molecular-weight oxidized materials (LMWOM) are produced on the polymer surface due to the dry treatment. ${ }^{5,30}$ Strobel et al. ${ }^{31}$ have reported that the LMWOM on the corona-treated polypropylene arises from the random cleavage of the polymer chain into a series of oligomers containing oxidized groups such as $\mathrm{COOH}, \mathrm{CHO}$ or $\mathrm{CH}_{2} \mathrm{OH}$. Such hydrophilic species can be dissolved into water. In fact, the weight recording of the second run of the treated film was not identical with that of the first run illustrated in Figure 1. Therefore, the wetting force measurement was carried out using the PET film samples rinsed with water and dried in air immediately after the dry processing. The obtained weight recordings

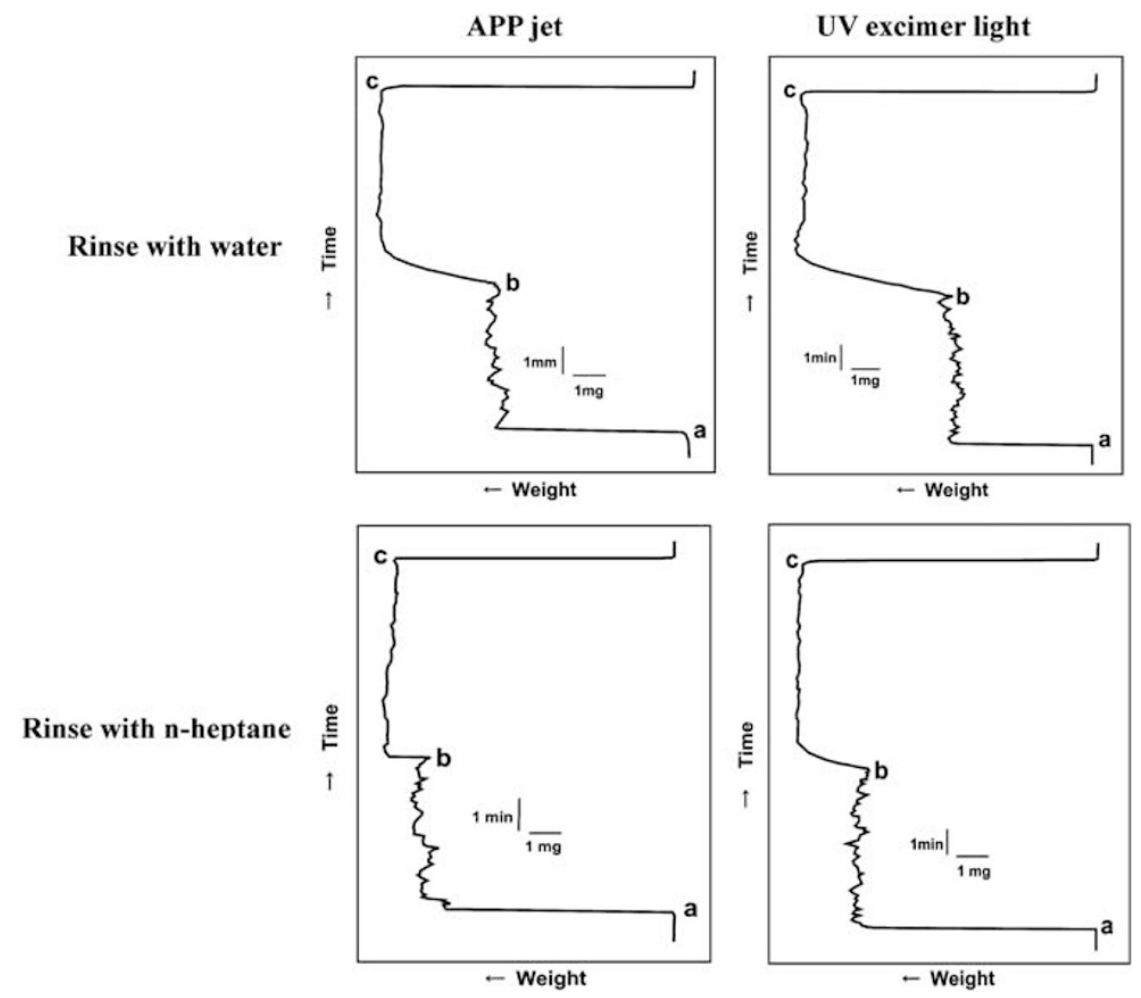

Figure 3 Typical weight recordings of the poly(ethylene terephthalate) films rinsed with water and $n$-heptane and dried in air immediately after treatment by atmospheric pressure plasma (APP) jet and ultraviolet (UV) excimer light. The measurements were carried out within 30 min after the treatment. The point a corresponds to the moment when the water surface touched the lower edge of the film, the point $b$ to when the direction of the motion of the water surface was reversed and the point $c$ to when the water surface was separated from the lower edge of the film. 
Table 1 The advancing and receding contact angles of water, $\underline{\theta}_{\mathrm{a}}$ and $\theta_{\mathrm{r}}$, on the PET films untreated and treated by APP and UV excimer light

\begin{tabular}{|c|c|c|c|c|c|c|}
\hline & \multicolumn{2}{|c|}{ Untreated } & \multicolumn{2}{|c|}{ APP jet } & \multicolumn{2}{|c|}{ UV excimer light } \\
\hline & $\theta_{a}$ (degree) & $\theta_{r}$ (degree) & $\theta_{a}$ (degree) & $\theta_{r}$ (degree) & $\theta_{a}$ (degree) & $\theta_{r}$ (degree) \\
\hline Rinse with water & - & - & $49.7 \pm 5.4$ & $20.5 \pm 1.1$ & $65.2 \pm 2.0$ & $20.8 \pm 1.3$ \\
\hline Rinse with $n$-heptane & - & - & $36.8 \pm 4.0$ & $21.3 \pm 1.2$ & $42.9 \pm 1.3$ & $19.5 \pm 1.1$ \\
\hline
\end{tabular}

Abbreviations: APP, atmospheric pressure plasma; PET, poly(ethylene terephthalate); UV, ultraviolet.

The measurements were carried out within 30 min after the treatment.

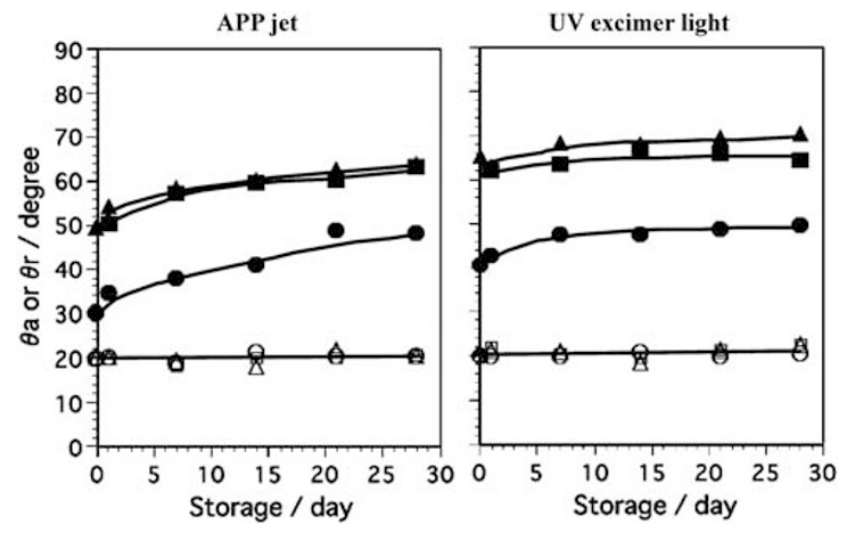

Figure 4 Changes in the advancing (closed symbols) and receding (open symbols) contact angles of water, $\theta_{\mathrm{a}}$ and $\theta_{\mathrm{r}}$, respectively, on the poly(ethylene terephthalate) film treated by atmospheric pressure plasma (APP) jet and ultraviolet (UV) excimer light as a function of the storage period. Circles, triangles and squares show without rinse, with rinse by water immediately after the treatment and with rinse by water immediately before the contact angle measurement, respectively.

are illustrated in Figure 3 (the upper two figures). Compared with the results of the APP- and UV-treated PET films without rinsing (see Figure 1), the advancing wetting force considerably decreased, but the receding one did not change. When the treated PET films were rinsed with non-polar $n$-heptane (Figure 3 , the lower two figures), both advancing and receding wetting forces were in good agreement with those for the treated PET films without rinsing as shown in Figure 1.

Table 1 presents the advancing and receding contact angles of water calculated from the corresponding wetting forces in Figures 1 and 3. It was clearly observed that both angles drastically decreased due to the dry processes. Although the decrement in advancing contact angle due to the treatment was remarkable for the APP exposure, the reproducibility of the angle obtained was better for the UV treatment. Longtime UV radiation in comparison with the APP processing at high speed may lead to the homogeneity of the treated surface.

In Table 1, the advancing angle considerably increased after rinsing with water, which was probably caused by the dissolution of the hydrophilic LMWOM on the treated PET surface into water as mentioned above. As expected, there was not very much change in the advancing angle after rinsing with $n$-heptane. On the other hand, the receding angles on the treated PET film were identical in all cases within experimental error because the LMWOM on the film was dissolved into water during the advancing scan.

Figure 4 shows the change in the water contact angles on the treated PET films with storage time. In all cases, an increase in the advancing contact angle was observed, which is from hydrophobic recovery due to the surface rearrangement of hydrophilic polymers via reorientation
Table 2 The advancing and receding contact angles, $\theta_{\mathrm{a}}$ and $\theta_{\mathrm{r}}$, respectively, the Lifshitz-van der Waals component, $\gamma^{\mathrm{LW}}$, Lewis acid parameter, $\gamma^{+}$, and Lewis base parameter, $\gamma^{-}$, of the surface-free energy, carbon, oxygen and nitrogen concentrations, and average roughness, root mean square roughness and maximum roughness depth, $\boldsymbol{R}_{\mathrm{a}}, \boldsymbol{R}_{\mathrm{ms}}$ and $\boldsymbol{R}_{\mathrm{max}}$, respectively, for the PET film surfaces untreated and treated by APP and UV excimer light

\begin{tabular}{|c|c|c|c|}
\hline & Untreated & APP jet & UV excimer light \\
\hline \multicolumn{4}{|c|}{ Water contact angle (degree) } \\
\hline$\theta_{\mathrm{a}}$ & $83.8 \pm 1.0$ & $58.5 \pm 2.0$ & $68.6 \pm 2.9$ \\
\hline$\theta_{\mathrm{r}}$ & $52.0 \pm 3.8$ & $19.4 \pm 0.9$ & $21.1 \pm 1.0$ \\
\hline \multicolumn{4}{|c|}{ Surface-free energy ( $\mathrm{mJ} \mathrm{m} \mathrm{m}^{-2}$; from advancing angles) } \\
\hline$\gamma^{\mathrm{LW}}$ & $38.6 \pm 1.5$ & $39.1 \pm 2.0$ & $42.0 \pm 1.0$ \\
\hline$\gamma^{+}$ & $0.2 \pm 0.1$ & $1.2 \pm 0.2$ & $0.9 \pm 0.1$ \\
\hline$\gamma^{-}$ & $3.3 \pm 0.9$ & $16.5 \pm 0.9$ & $9.6 \pm 0.8$ \\
\hline
\end{tabular}

Surface-free energy ( $\mathrm{mJ} \mathrm{m} \mathrm{m}^{-2}$; from receding angles)

$\begin{array}{lrrr}\gamma^{\mathrm{LW}} & 48.3 \pm 0.6 & 49.1 \pm 0.2 & 48.6 \pm 0.5 \\ \gamma^{+} & 0.1 \pm 0.1 & 0.0 \pm 0.0 & 0.0 \pm 0.0 \\ \gamma^{-} & 26.5 \pm 1.6 & 59.2 \pm 0.5 & 57.9 \pm 0.4\end{array}$

Atomic concentration (\%)

$\begin{array}{cccc}\mathrm{C} & 74.7 & 65.3 & 67.8 \\ \mathrm{O} & 25.3 & 33.3 & 32.2 \\ \mathrm{~N} & - & 1.4 & -\end{array}$

Surface roughness ( $\mathrm{nm}$ )

$\begin{array}{lccc}R \mathrm{~ms} & 0.73 & 1.53 & 2.12 \\ R_{\mathrm{a}} & 0.58 & 1.23 & 1.63 \\ R \max & 7.10 & 13.23 & 21.42\end{array}$

Abbreviations: APP, atmospheric pressure plasma; UV, ultraviolet. Rinse by water immediately after the treatment, storage for 1 week.

and migration. ${ }^{22,23}$ The hydrophobic recovery was found to be larger for the film without rinsing (Figure 4, closed circles) compared with that rinsed by water (Figure 4, triangles and squares), indicating that the loss of LMWOM to the atmosphere and the surface arrangement occurred. During the storage period, the advancing angles on the PET film rinsed with water immediately after the treatment (Figure 4, closed triangles) were slightly larger than those rinsed by water immediately before the contact angle measurement (Figure 4, closed squares), which suggests that the LMWOM can suppress the surface rearrangement mentioned above. For the UV-treated films, the hydrophobic recovery almost disappeared only after a week, that is, their wettability stability was achieved more rapidly than that of the APPtreated film. It is assumed that the depth of UV penetration makes it 
difficult for polymer chains to migrate to the top of the PET surface and provides low hydrophobic recovery. ${ }^{32}$

Surprisingly, the receding contact angles remained almost a constant value $\left(\sim 20^{\circ}\right)$, independent of the rinse and storage. It was shown in the previous paper ${ }^{26}$ that such contact angle hysteresis behavior on the PET surface after treatment by the APP is consistent with the theoretical calculation of the advancing and receding contact angles on the model heterogeneous surfaces with low- and high-energy regions. ${ }^{33,34}$ For predominately high-energy surfaces such as the APP- and UV-treated PET surfaces, only the advancing contact angle is strongly dependent on the proportion of the high-energy region. In the hydrophobic recovery process due to rinsing with water and storing in air after the dry processing, the high-energy region proportion can decrease. In this process, the receding angle will be insensitive to the decrease in the high-energy region proportion. Therefore, hydrophobic recovery was observed only for the advancing contact angle, and the receding angle remained constant.

\section{Surface characteristics of PET treated by dry processing}

The results of the surface characterization are summarized in Table 2. The APP- and UV-treated films were analyzed after rinsing with water and aging for 1 week, where the hydrophobic recovery almost ceased and the treated surface was stabilized.

The advancing and receding contact angles of the PET surface were found to decrease drastically after the treatments of APP and UV. Because the contact angle determined by the Wilhelmy method is not an observed angle, but an intrinsic angle, ${ }^{29}$ the increase in the wettability may be caused by the change in the surface chemical composition, not by the topographical change. After the APP and the UV treatments, the surface-free energy determined from the contact angle measurement and the surface oxygen concentration determined from the XPS survey spectra were found to increase. Figures 5 and 6 illustrate the deconvoluted high-resolution XPS C1s and O1s spectra, respectively, for the film before and after the APP and the UV treatments. It is clearly observed that the ratio of $\mathrm{C}-\mathrm{O}$ and $\mathrm{O}-\mathrm{C}=\mathrm{O}$ groups from the $\mathrm{C} 1 \mathrm{~s}$ spectrum and $\mathrm{C}-\mathrm{O}$ group from the $\mathrm{O} 1$ s spectrum on the PET surface increased after the treatments. Such oxygencontaining functional groups may enhance the Lewis base (electron donor) parameter that is responsible for the hydrophilic character. ${ }^{35}$ Therefore, it was concluded that the wettability increase was due to the increase in the base parameter of the surface-free energy by the introduction of the oxygen-containing surface functional groups due to exposure to APP and UV. ${ }^{12,29,36-38}$ In fact, the increases in the
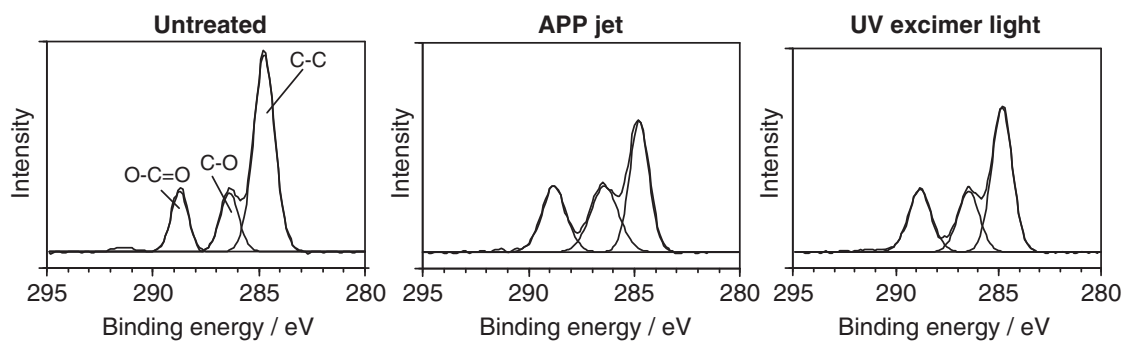

Figure 5 X-ray photoelectron spectroscopy $\mathrm{C} 1 \mathrm{~s}$ core level spectra of poly(ethylene terephthalate) film surfaces before and after the treatments by atmospheric pressure plasma (APP) jet and ultraviolet (UV) excimer light. The films were rinsed with water immediately after the treatments and stored for 1 week.
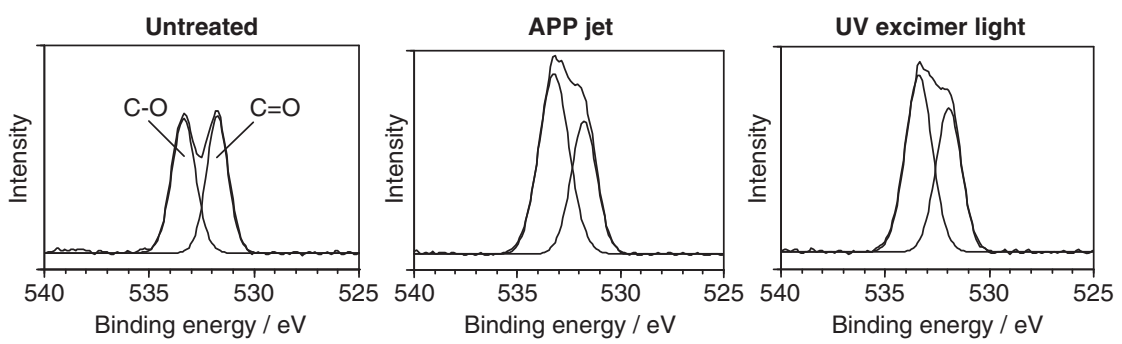

Figure 6 X-ray photoelectron spectroscopy 01s core level spectra of poly(ethylene terephthalate) film surfaces before and after the treatments by atmospheric pressure plasma jet and ultraviolet excimer light. The films were rinsed with water immediately after the treatments and stored for 1 week.
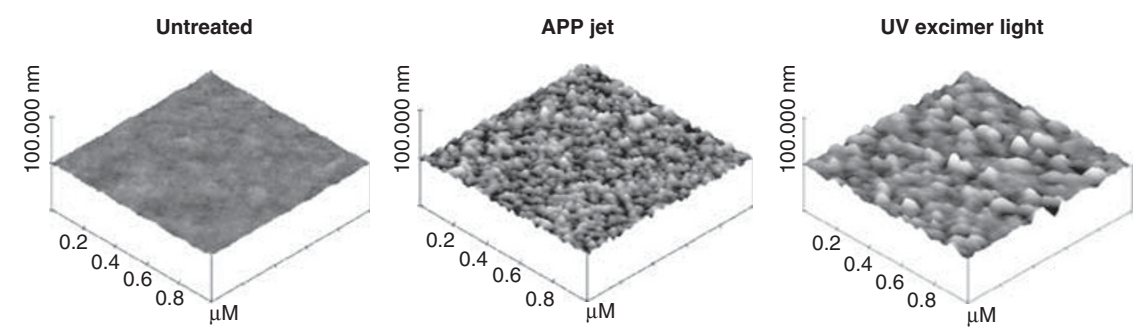

Figure 7 Atomic force microscopy images of poly(ethylene terephthalate) film surfaces before and after the treatments by atmospheric pressure plasma (APP) jet and ultraviolet (UV) excimer light. 
wettability, the surface-free energy and the surface oxidation of the PET were remarkable after the APP treatment compared with the UV treatment.

The surface roughness parameters of the PET film, which was obtained from the atomic force microscopy images in Figure 7, increased due to the dry processes, especially for the UV treatment. It has been reported that a remarkable topographical change on polymer surfaces is observed when inert $\mathrm{Ar} / \mathrm{He} \mathrm{gas}^{37}$ and a UV excimer laser ${ }^{39,40}$ are used for the APP and the UV treatments, respectively. Surface roughness control of PET by dry processes is the subject for a future study.

In general, APP contains a variety of active species such as radicals, ions, excited molecules and electrons, which may simultaneously interact with the exposed PET surface. ${ }^{18}$ In the case of UV irradiation, photochemical reactions are the main reactions that occur. ${ }^{20}$ These dry processes are initiated by the decomposition of excited macromolecules and the formation of free radicals. Such radicals react with activated oxygen species generated through the photoexcitation of atmosphere oxygen molecules. ${ }^{41}$ Reaction mechanisms in APP and UV may have effects on the wettability of the treated PET surface and the subsequent hydrophobic recovery behavior due to the loss of LMWOM to the atmosphere and the surface arrangement. However, within the experimental data in this study, it is difficult to explain the reaction mechanism of the two dry processes. Careful consideration on the basis of further experiments is the subject of a future study.

\section{CONCLUSIONS}

Two dry processes, APP jet exposure and UV excimer light irradiation, were applied to alter the physicochemical properties of the PET film surface. The advancing and receding contact angles of water on the PET film decreased drastically after both processes. Although the decrement in the advancing contact angle due to the treatment was remarkable for the APP exposure, the reproducibility of the obtained angle was better for the UV treatment. The wettability increase was attributed to the increase in the base parameter of the surface-free energy by the introduction of the oxygen-containing surface functional groups due to exposure to APP and UV. Although the advancing angle was found to increase with rinsing due to water and with aging time in air, the receding angle remained almost the same. It was suggested that the rinsing with water after the processing made it possible to suppress the following hydrophobic recovery in air. The hydrophobic recovery disappeared more rapidly for the UV-treated film than the APP-treated film. The wettability stability of the treated surface is one of the greatest interests in polymer surface modification by dry processes. The experimental findings in this study will provide useful information for stabilizing the treated surface in practical applications.

\section{ACKNOWLEDGEMENTS}

Gratitude is expressed to the Ministry of Education, Sports, Culture, Science and Technology, Japan for a Grant-in-Aid for Scientific Research (grant number 20300236) to carry out this work.

1 Iroh, J. O. Poly(ethylene terephthalate). in Polymer Data Handbook (ed. Mark, J. E.) 558-560 (Oxford University Press, New York Oxford, 1999).

2 DeLassus, P. T. \& Whiteman, N. F. Physical and mechanical properties of some important polymers. in Polymer Handbook. 4th (eds. Brandrup, J., Immergut, E. H., Grulke, E. A., Abe, A. \& Bloch, D. R.) V159-V169 (John Wiley \& Sons, New York, 1999).
3 Kim, E.- Y., Kong, J.- S., An, S.- K. \& Kim, H.- D. Surface modification of polymers and improvement of the adhesion between evaporated copper metal film and a polymer. 1. Chemical modification of PET. J. Adhesion Sci. Technol. 9, 1119-1130 (2000).

4 Wefers, L., Knittel, D., Bosbach, D., Rammensee, W. \& Schollmeyer, E. Surface reconstruction of UV-laser irradiated poly(ethylene terephthalate) by atomic force microscopy. Appl. Surface Sci. 59, 267-271 (1992).

5 Walzak, M. J., Flynn, S., Foerch, R., Hill, J. M., Karbashewski, E., Lin, A. \& Strobel, M. UV and ozone treatment of polypropylene and poly (ethylene terephthalate). J. Adhesion Sci. Technol. 9, 1229-1248 (1995).

6 Zhang, Z. Y., Boyd, I. W. \& Esrom, H. Surface modification of polyethylene terephthalate with excimer UV radiation. Surface Interface Anal. 24, 718-722 (1996).

7 Le, Q. T., Pireaux, J. J., Caudano, R., Leclere, P. \& Lazzaroni, R. XPS/AFM study of the PET surface modified by oxygen and carbon dioxide plasmas: Al/PET adhesion. J. Adhesion Sci. Technol. 12, 999-1023 (1998).

8 Wong, W., Chan, K., Yeung, K. W. \& Lau, K. S. Chemical modification of poly(ethylene terephthalate) induced by laser treatment. Textile Res. J. 71, 117-120 (2001).

9 Petit, S., Laurens, P., Barthes-Labrousse, M. G., Amouroux, J. \& Aréfi-Khonsari, F. Al/ PET adhesion: role of an excimer laser pretreatment of PET prior to aluminum thermal evaporation. J. Adhes. Sci. Technol. 17, 353-368 (2003).

10 Gotoh, K. Wettability and surface free energies of polymeric materials exposed to excimer ultraviolet light and particle deposition onto their surfaces in water. in Polymer Surface Modification: Relevance to Adhesion Vol. 3 (ed. Mittal, K.L.) 125-137 (VSP, Utrecht, 2004).

11 Almazán-Almazán, M. C., Paredes, J. I., Pérez-Mendoza, M., Domingo-García, M., López-Garzón, F. J., Martínez-Alonso, A. \& Tascón, J. M. D. Effects of oxygen and carbon dioxide plasmas on the surface of poly(ethylene terephthalate). J. Colloid Interface Sci. 287, 57-66 (2005).

12 Almazán-Almazán, M. C., Paredes, J. I., Pérez-Mendoza, M., Domingo-García, M., López-Garzón, F. J., Martínez-Alonso, A. \& Tascón, J. M. D. Surface characterisation of plasma-modified poly(ethylene terephthalate). J. Colloid Interface Sci. 293, 353-363 (2006).

13 Bogaerts, A., Neyts, E., Gijbels, R. \& van der Mullen, J. Gas discharge plasmas and their applications. Spectrochimica Acta Part B 57, 609-658 (2002).

14 Lu, X., Xiong, Q., Xiong, Z., Hu, J., Zhou, F., Gong, W., Xian, Y., Zou, C., Tang, Z., Jiang, Z. \& Pan, Y. Propagation of an atmospheric pressure plasma plume. J. Appl. Phys 105, 043304 (2009).

15 Jiang, N., Ji, A. \& Cao, Z. Atmospheric pressure plasma jet: Effect of electrode configuration, discharge behavior, and its formation mechanism. J. Appl. Phys. 106, 013308 (2009).

$16 \mathrm{Lu}, \mathrm{X}$. \& Laroussi, M. Dynamics of an atmospheric pressure plasma plume generated by submicrosecond voltage pulses. J. Appl. Phys. 100, 063302 (2006).

17 Friedrich, J. F., Unger, W., Lippitz, A., Gross, T., Rohrer, P., Saur, W., Erdmann, J. \& Gorsler, H. V. The improvement in adhesion of polyurethane-polypropylene composites by short-time exposure of polypropylene to low and atmospheric pressure plasmas. J. Adhesion Sci. Technol. 9, 575-598 (1995).

18 Yamakawa, K., Hori, M., Goto, T., Den, S., Katagiri, T. \& Kano, H. Ultrahigh-speed etching of organic films using microwave-excited nonequilibrium atmospheric-pressure plasma. J. Applied Phys. 98, 043311 (2005)

19 Moravej, M., Yang, X., Hicks, R. F., Penelon, J. \& Babayan, S. E. A radio-frequency nonequilibrium atmospheric pressure plasma operating with argon and oxygen. J. Appl. Phys. 99, 093305 (2006).

20 Song, Q. \& Netravali, A. N. Excimer laser surface modification of ultra-high-strength polyethylene fibers for enhanced adhesion with epoxy resins. Part 1. Effect of laser operating parameters. J. Adhesion Sci. Technol. 12, 957-982 (1998).

21 Esrom, H., Seebock, R., Charbonnier, M. \& Romand, M. Surface modification of polyimide with dielectric barrier discharges and with dielectric barrier discharge driven excimer UV lamps. in Polymer Surface Modification: Relevance to Adhesion Vol. 2 (ed. Mittal, K. L.) 335-354 (VSP, Utrecht, 2000).

22 Owen, M. J. \& Smith, P. J. Plasma treatment of polydimethylsiloxane. J. Adhesion Sci. Technol. 8, 1063-1075 (1994).

23 Kim, B. K., Kim, K. S., Cho, K. \& Park, C. E. Retardation of the surface rearrangement of $\mathrm{O}_{2}$ plasma-treated LDPE by a two-step temperature control. J. Adhesion Sci. Technol. 15, 1805-1816 (2001).

24 Tagawa, M., Yasukawa, A., Gotoh, K., Tagawa, M., Ohmae, N. \& Umeno, M. Local deviation in contact angles on heterogeneous fibrous solids. J. Adhesion Sci. Technol. 6, 763-776 (1992).

25 Takemura, Y., Yamaguchi, N. \& Hara, T. Study on surface modification of polymer films by using atmospheric plasma jet source. Jpn. J. Appl. Phys. 47, 5644-5647 (2008).

26 Gotoh, K., Yasukawa, A. \& Taniguchi, K. Water contact angles on poly (ethylene terephthalate) film exposed to atmospheric pressure plasma. J. Adhesion Sci. Technol. 25, 307-322 (2011)

27 Tagawa, M., Gotoh, K., Yasukawa, A. \& Ikuta, M. Estimation of surface free energies and Hamaker constants for fibrous solids by wetting force measurements. Colloid Polym. Sci. 268, 589-594 (1990).

28 van Oss, C. J., Good, R.J. \& Chaudhury, M.K. Additive and nonadditive surface tension components and the interpretation of contact angles. Langmuir 4, 884-891 (1988).

29 Gotoh, K., Tagawa, M., Ohmae, N., Kinoshita, H . \& Tagawa, M. Surface characterization of atomic oxygen beam-exposed polyimide films using contact angle measurements. Colloid Polym. Sci. 279, 214-220 (2001).

30 Everaert, E. P., van der Mei, H. C. \& Busscher, H. J. Hydrophobic recovery of repeatedly plasma-treated silicone rubber. Part 2, A comparison of the hydrophobic recovery in air, water, or liquid nitrogen. J. Adhesion Sci. Technol. 10, 351-359 (1996). 
31 Strobel, M., Jones, V., Lyons, C. S., Ulsh, M., Kushner, M. J., Dorai, R. \& Branch, M. C. A comparison of corona-treated and flame-treated polypropylene films. Plasmas and Polymers 8, 61-95 (2003).

32 de Menezes Atayde, C. \& Doi, I. Highly stable hydrophilic surfaces of PDMS thin layer obtained by UV radiation and oxygen plasma treatments. Phys. Status Solidi C 7, No. 2 189-192 (2010).

33 Johnson, R. E. Jr. \& Dettre, R. H. Contact angle hysteresis, III. Study of an idealized heterogeneous surface. J. Phys. Chem. 68, 1744-1750 (1964).

34 Johnson, R. E. Jr. \& Dettre, R. H. Contact angle hysteresis. IV. Contact angle measurements on heterogeneous surfaces. J. Phys. Chem. 69, 1507-1515 (1965).

35 Good, R. J. Contact Angle, Wettability and Adhesion: a critical review. in Contact Angle, Wettability and Adhesion (ed. Mittal, K. L.) 3-36 (VSP, Utrecht, 1993).

36 Sancaktar, E. \& Lu, H. The effects of excimer laser irradiation on the surface morphology and self-adhesion properties of some engineering polymers as evaluated by ultrasonic welding. in Polymer Surface Modification: Relevance to Adhesion Vol. 3 (ed. Mittal, K. L.) 183-242 (VSP, Utrecht, 2004).

37 Kwon, O.-J., Myung, S.-W., Lee, C.-S. \& Choi, H.-S. Comparison of the surface characteristics of polypropylene films treated by $\mathrm{Ar}$ and mixed gas $\left(\mathrm{Ar} / \mathrm{O}_{2}\right)$ atmospheric pressure plasma. J. Colloid Interface Sci. 295, 409-416 (2006).

38 Leroux, F., Campagne, C.., Perwuelz, A . \& Gengembre, L. Polypropylene film chemical and physical modifications by dielectric barrier discharge plasma treated at atmospheric pressure. J. Colloid Interface Sci. 328, 412-420 (2008).

39 Tokarev, V. N., Lazare, S., Belin, C. \& Debarre, D. Viscous flow and ablation pressure phenomena in nanosecond UV laser irradiation of polymers. Appl. Phys. A79, 717-720 (2004).

40 Rubahn, K., Ihlemann, J., Jakopic, G., Simonsen, A. C. \& Rubahn, H.- G. UV laserinduced grating formation in PDMS thin films. Appl. Phys. A79, 1715-1719 (2004).

41 Hozumi, A., Inagaki, H. \& Kameyama, T. The hydrophilization of polystyrene substrates by 172-nm vacuum ultraviolet light. J. Colloid Interface Sci. 278, 383-392 (2004). 